\title{
Differential Changes of Left Ventricular Myocardial Deformation in Three-vessel Critical Stenosis CAD Patients with and without Diabetes: A Two- dimensional Speckle-tracking Echocardiography- based Study.
}

luying jiang

Shihezi University

jingbo liu

Huazhong University of Science and Technology Tongji Medical College

zhenjia yang

Shihezi University

li wang ( $\nabla$ gls101012021@163.com )

Shihezi University

houjuan zuo

Huazhong University of Science and Technology Tongji Medical College

Original investigation

Keywords: speckle tracking imaging, strain, type 2 diabetes mellitus, coronary artery disease, three-vessel CAD, myocardial ischemia

Posted Date: June 30th, 2021

DOl: https://doi.org/10.21203/rs.3.rs-658195/v1

License: (c) (i) This work is licensed under a Creative Commons Attribution 4.0 International License.

Read Full License 


\section{Abstract}

\section{Background}

Though the presence of three-vessel disease (3VD) coronary artery disease (CAD) among patients with type 2 diabetes mellitus (T2DM) is relatively common, very limited data is regarding their left ventricular (LV) function. The purpose of our study is to assess the LV function in 3VD patients with T2DM by twodimensional speckle tracking echocardiography (2-D STE).

\section{Methods}

Hundred-three consecutive patients with confirmed 3VD CAD were enrolled and divided into two groups, 53 patients with DM and 50 patients without DM. The control group was composed of 30 ageand sex-matched healthy individuals. Echocardiography was performed at baseline before coronary angiography. The 2-D STE was used to measure LV global longitudinal strain (GLS) and segmental peak systolic longitudinal strains (PSLSs).

\section{Result}

By standard echocardiogram, there is no significant difference between 3VD-DM and 3VD-non-DM groups. Strains measured by 2-D STE showed that the 3VD-DM patients have significantly lower global longitudinal strain (GLS) than the 3VD-non-DM patients (15.87 \pm 2.51 vs. $17.56 \pm 2.72, P<0.05)$. Further, in the 3VD-DM groups, the duration of the DM and glucose control level were investigated. Our results showed that GLS of the duration of $D M \geq 5$ of $3 V D$ was significantly lower than that in $3 V D$ patients with duration of $\mathrm{DM}<5$, especially in global PSLS ( $14.25 \pm 2.31$ vs. $16.65 \pm 1.96, P=0.007)$, mid PSLS $(14.08 \pm$ 3.72 vs. $16.51 \pm 2.15 \otimes P=0.017)$, and apical PSLS $(15.26 \pm 3.28$ vs. $18.44 \pm 4.36 \rrbracket \mathrm{p}=0.049)$. However, the results of the glucose control level showed no difference on GLS between the 3VD patients with HbA1c $\geq$ $7 \%$ and $\mathrm{HbA} 1 \mathrm{c}<7 \%$.

\section{Conclusions}

Global and segmental peak systolic longitudinal strains (PSLSs) are significantly lower in 3VD-DM patients than in the patients with 3VD only. The duration of diabetes is an important factor cause the decrease GLS in 3VD-DM patients. However, the glucose control level has limited influence on LV function in 3VD patients.

\section{Background}

The prevalence of type 2 diabetes mellitus (T2DM) is rapidly increasing, as a result the number of people with T2DM worldwide has more than doubled over the past three decades [1]. T2DM could contribute to left ventricular (LV) structure and function from normal to dysfunction [2]. The pathology of myocardial dysfunction of T2DM is likely multifactorial and includes increased oxidative stress [3], microangiopathy [4], altered myocardial metabolism and myocardial fibrosis [5]. Coronary artery disease (CAD) is one of 
the most leading causes of morbidity and mortality in individuals with T2DM [6]. Moreover, T2DM is known as a significant factor more likely leading to multiple vessels $C A D$, especially three-vessel disease (3VD) [7]. The 3VD, the severe CAD, was three major coronary arteries occluded [8]. It was reported that the overall frequency of $3 \mathrm{VD}$ among the non-ST Segment elevation myocardial infarction patients was $30.2 \%$, and the frequency of 3VD in patients with DM comorbidity was much higher [9]. The presence of $3 \mathrm{VD}$ in the patients with DM is more and more common. However, very limited data is available regarding its clinical significance.

The recent development of two-dimensional speckle tracking echocardiography (2-D STE), also known as deformation imaging, has been introduced as a quantitative means to objectively assess regional myocardial function [10]. In comparison with traditional methods, myocardial strain has better diagnostic power in detecting clinically unapparent LV dysfunction caused by DM or CAD [11]. Previous studies reported that global systolic longitudinal strain (GLS) is significantly lower in the patients with uncomplicated DM and even in pre-diabetic patients and patients with impaired glucose tolerance [12]. Additionally, GLS was significantly lower in the DM patients with obstructive CAD than in patients without [13]. Further, researchers have claimed that GLS could be used to predict DM or CAD, whereas the changes of GLS in patients with both DM and three-vessel CAD are often not detected by resting echocardiography.

In this study, we investigated the global and segmental longitudinal strain by 2-D speckle tracking in the 3VD patients with DM. Particularly, the effects of the duration or the glucose control level of DM on the LV function of patients were evaluated. Our aim was to evaluate whether global and/or segmental longitudinal strain measured by 2-D STE could be a useful method for detecting LV functional changes in diabetic patients with three-vessel CAD.

\section{Methods}

\subsection{Study population}

The patients (from 1 Nov 2018 and 30 Nov 2020) referred for evaluation of chest pain or the presence of CAD were admitted to Tongji Hospital, Huazhong University of Science and Technology. These patients who had under gone echocardiography and subsequently coronary angiography (CAG) within $7 \mathrm{~d}$ for initial screening were included. In total, 103 patients with three-vessel critical stenosis CAD proved by CAG were prospectively enrolled in this study[14]. Patients were excluded if they met any of the following criteria:(1) overt LV systolic dysfunction with left ventricular ejection fraction (LVEF) $<50 \%$; (2) a previous history of open-heart surgery; (3) severe types of renal dysfunction defined as glomerular filtration rate $<30 \mathrm{~mL} / \mathrm{min} / 1.73 \mathrm{~m}^{2}$; (4) hypertension $>180 / 100 \mathrm{mmHg}$ uncontrollable despite medical therapy; (5)significant valvular heart disease; (6) inadequate quality of images that were non-analyzable by the software; and (7) severe arrhythmia. Further, according to the presence of type $2 \mathrm{DM}$, the total 103 subjects were divided into the 3VD with type $2 \mathrm{DM}$ (3VD-DM) and without type 2 DM group (3VD-non-DM). For comparison, a control group randomly taken from our 
database by the observers who had no involvement in echocardiographic analysis, which had a similar age, gender and LVEF distribution, consisting of 30 subjects without a history of DM and with negative results of coronary angiography in the major epicardial coronary arteries served. Finally, the groups were as the 3VD-DM group, the 3VD-non-DM group, and the control group.

The definition of three-vessel critical stenosis was as all three epicardial vessels damaged with stenosis $\geq 50 \%$ and at least one vessel with stenosis $\geq 70 \%$ in the coronary angiography performed.

All procedures were in accordance with the ethical standards of the responsible committee on human experimentation (institutional and national) and with the Helsinki Declaration of 1975, as revised in 2000. Informed consent was obtained from all patients included in the study. And this study was approved by the Research Ethics Committee of Tongji Hospital.

\subsection{Echocardiographic examination}

All echocardiographic studies were performed using a commercially available echocardiographic system within at least 3 days prior to coronary angiography $\bigotimes$ by means of a $3.5 \mathrm{MHz}$ transducer on a single commercially echocardiographic system (Vivid E9; GE Vingmed; Horten, Norway). Digital routine grayscale two-dimensional cine loops from three consecutive heart beats were obtained at end-expiratory apnea from standard parasternal and apical views. Sector width was optimized to allow for complete myocardial visualization while maximizing the frame rate. Routine examinations included measurements of cardiac dimensions, volumes, peak velocities of early $(E)$ and late $(A)$ diastolic flow, the E/A ratio and LVEF. LV volumes and LVEF were calculated using the modified biplane Simpson's method. Standard echocardiographic measurements were obtained according to the current guidelines of the American society of echocardiography/European association of cardiovascular imaging [15].

\subsection{Speckle-tracking strain analysis}

Speckle-tracking strain analysis was performed for each patient with the aid of a single dedicated software to evaluate LV longitudinal function, in terms of GLS. Two-dimension gray-scale harmonic images were obtained from each of three standard apical (apical long-axis, four-chamber and twochamber) views, and three consecutive cardiac cycles of each view were saved in digital format for offline strain analysis. All images were captured at a frame rate of between 40 and $60 \mathrm{fps}$ with a single focus. LV global and segmental longitudinal strains were quantified using Echo Pac (GE Vingmed) by automated function imaging (AFI) [15]. Longitudinal speckle-tracking strain was calculated by means of an automated contouring detection algorithm, and allowed the operator further adjustment of the region of interest to improve the tracking quality. The automated algorithm provided quantitative measurements of global and segmental peak systolic longitudinal strains (PSLSs) in a single bull's-eye summary. GLS was determined as the averaged peak strain of 18 segments from the three standard apical views, and was expressed as an absolute value in accordance with current guidelines. 


\subsection{Statistical analysis}

Continuous variables were expressed as mean values and standard deviation for normally distributed data and median and interquartile range for non-normally distributed data, while categorical variables were expressed as frequencies and percentages. One-way analysis of variance with post hoc analysis by Bonferroni's was used to compare continuous variables and Chi-square test or Fisher's exact test for categorical variables.

Independent associations of GLS with clinical and echocardiographic parameters in 3VD with DM were evaluated by means of multiple regression analysis.

The intraclass correlation coefficient was used to determine inter- and intra-observer reproducibility for GLS from 20 randomly selected subjects. For all steps, a p value of $<0.05$ was regarded as statistically significant. All analyses were performed with SPSS version 20.0 software.

\section{Results}

\subsection{Baseline characteristics}

The baseline clinical characteristics of the patients are summarized in Table 1. The patients of 3VD-DM were younger and had higher incidences risk factors of hypertension than those the 3VD-non-DM group. In addition, some medications, such as angiotensin-converting enzyme inhibitors and angiotensin II receptor blockers, were more frequently taken by the 3VD-DM patients. There were no significant differences in baseline characteristics of male§weight and body mass index among the 3VD-DM, 3VDnon-DM and control groups. 
Table 1

Characteristics of the patient population

\begin{tabular}{|c|c|c|c|c|}
\hline & $\begin{array}{l}\text { 3VD-DM } \\
(n=53)\end{array}$ & $\begin{array}{l}\text { 3VD-non-DM } \\
(n=50)\end{array}$ & Control $(n=30)$ & $\begin{array}{l}P- \\
\text { value }\end{array}$ \\
\hline Male『n(\%) & $38(71.69)$ & $34(68.00)$ & $14(46)$ & 0.074 \\
\hline Age(year) & $59.34 \pm 8.25$ & $60.76 \pm 8.57^{\star}$ & $54.35 \pm 10.24$ & 0.011 \\
\hline Height(cm) & $\begin{array}{l}164.21 \pm \\
6.52\end{array}$ & $164.60 \pm 7.28$ & $164.64 \pm 8.25$ & 0.965 \\
\hline Weight(kg) & $\begin{array}{l}68.14 \pm \\
10.30\end{array}$ & $65.63 \pm 10.64$ & $67.19 \pm 14.15$ & 0.536 \\
\hline Body surface area $\left(\mathrm{m}^{2}\right)$ & $1.74 \pm 0.14$ & $1.73 \pm 0.17$ & $1.72 \pm 0.21$ & 0.836 \\
\hline Body mass index $\left(\mathrm{kg} / \mathrm{m}^{2}\right)$ & $25.31 \pm 2.83$ & $24.15 \pm 3.13$ & $24.66 \pm 4.31$ & 0.309 \\
\hline \multicolumn{5}{|l|}{ Risk factors } \\
\hline Hypertention,n(\%) & $43(81)$ & $36(72)$ & $7(23)$ & $<0.001$ \\
\hline Smoking,n(\%) & $24(45)$ & $22(44)$ & $8(26)$ & 0.236 \\
\hline $\begin{array}{l}\text { Cerebrovascular } \\
\text { accident,n(\%) }\end{array}$ & $5(9)$ & $4(8)$ & $0(0)$ & 0.357 \\
\hline Dyslipidaemia,n(\%) & $19(36)$ & $19(38)$ & $7(23)$ & 0.437 \\
\hline $\begin{array}{l}\text { Systolic blood pressure } \\
(\mathrm{mmHg})\end{array}$ & $\begin{array}{l}138.18 \pm \\
18.32\end{array}$ & $137.46 \pm 21.13$ & $132.42 \pm 17.01$ & 0.451 \\
\hline $\begin{array}{l}\text { Diastolic blood pressure } \\
(\mathrm{mmHg})\end{array}$ & $\begin{array}{l}82.13 \pm \\
11.80\end{array}$ & $80.10 \pm 13.25$ & $81.78 \pm 8.23$ & 0.648 \\
\hline Heart rate $(\mathrm{bpm})$ & $\begin{array}{l}75.22 \pm \\
10.16\end{array}$ & $71.24 \pm 10.01$ & $70.04 \pm 8.96$ & 0.079 \\
\hline \multicolumn{5}{|l|}{ Serum maker } \\
\hline Cholesterol (mmol/l) & $4.35 \pm 1.51$ & $4.30 \pm 1.17$ & $3.98 \pm 0.85$ & 0.453 \\
\hline Triglycerides $(\mathrm{mmol} / \mathrm{l})$ & $1.78 \pm 1.36$ & $1.64 \pm 1.24$ & $1.69 \pm 0.33$ & 0.912 \\
\hline $\mathrm{HDL}(\mathrm{mmol} / \mathrm{l})$ & $0.93 \pm 0.24$ & $0.96 \pm 0.22$ & $1.03 \pm 0.25$ & 0.271 \\
\hline $\operatorname{LDL}(\mathrm{mmol} / \mathrm{l})$ & $2.74 \pm 1.25$ & $2.61 \pm 1.19$ & $2.30 \pm 0.81$ & 0.343 \\
\hline creatinine $(\mu \mathrm{mol} / \mathrm{l})$ & $76.81 \pm 21.39$ & $80.80 \pm 19.93$ & $70.32 \pm 14.88$ & 0.076 \\
\hline Glucose (mg/dl) & $\underset{* \#}{7.92} \pm 2.63$ & $5.42 \pm 0.71$ & $5.34 \pm 0.65$ & $<0.001$ \\
\hline
\end{tabular}

Medication prior to coronary angiography 


\begin{tabular}{ccccc} 
Aspirin,n (\%) & $13(24)$ & $13(26)$ & $7(23)$ & 0.991 \\
\hline Statin,n (\%) & $11(21)$ & $14(28)$ & $5(16)$ & 0.564 \\
\hline b-blocker,n (\%) & $6(11)$ & $10(20)$ & $6(20)$ & 0.481 \\
\hline $\begin{array}{c}\text { ARB and/or ACE } \\
\text { inhibitor,n(\%) }\end{array}$ & $14(26)$ & $5(10)$ & $2(6)$ & 0.002 \\
\hline $\begin{array}{c}\text { Calcium channel blocker,n } \\
(\%)\end{array}$ & $14(26)$ & $9(18)$ & $5(16)$ & 0.406 \\
\hline Nitrate agent,n (\%) & $15(28)$ & $14(28)$ & $9(30)$ & 0.938
\end{tabular}

$3 V D$, three-vessel disease; $D M \otimes$ diabetes mellitus $\mathbb{H} H D L$, high density lipoprotein; $L D L$, low density lipoprotein; ARB, angiotensin $₫$ receptor antagonist; ACE, angiotensin converting enzyme. $P$-value using Chi-square test or one-way analysis of variance.

${ }^{\star} P<0.05$ compared with the control group. ${ }^{\#} P<0.05$ compared with the 3VD-non-DM group.

\subsection{Angiography data of the study population}

The data of coronary angiography are shown in Table 2. In summary, 103 patients had significant stenosis in three coronary arteries, and the control 30 patients had normal coronary anatomy or $<50 \%$ stenosis. The 3VD-DM group had more incidence of high-grade stenotic lesions (HSL) than the group of 3 VD-non-DM ( $59 \%$ vs. $30 \% ; P=0.004)$. Areas relating to $\mathrm{HSL}$, stenosis was found more frequently in the left circumflex artery in the 3VD-DM group than in the 3VD-non-DM group ( $25 \%$ vs. $8 \% ; P=0.017)$. However, no significant difference was observed of stenosis in the left anterior descending artery and right coronary artery between the 3VD-DM and 3VD-non-DM. 
Table 2

Angiographic findings of study patients by group
$\mathrm{n}(\%)$
3VD-DM ( $\mathrm{n}=53)$
3VD-non-DM $(n=50)$
Control $(n=30)$
$P$-value

Diseased vessel

\begin{tabular}{lllll} 
LMCA & $5(9)$ & $11(22)$ & N/A & 0.104 \\
\hline LAD & $49(93)$ & $49(98)$ & N/A & 0.978 \\
\hline LCX & $48(91)$ & $47(94)$ & N/A & 0.75 \\
\hline RCA & $48(91)$ & $47(94)$ & N/A & 0.75 \\
\hline HSL & & & & \\
\hline 1 HSL & $31(59)^{\#}$ & $15(30)$ & N/A & 0.002 \\
\hline $2 H S L$ & $25(47)^{\#}$ & $15(30)$ & N/A & 0.045 \\
\hline $3 H S L$ & $3(6)$ & $0(0)$ & N/A & 0.243 \\
\hline
\end{tabular}

Location of HSL

\begin{tabular}{lllll}
\hline LMCA & $0(0)$ & $0(0)$ & N/A & - \\
\hline LAD & $10(19)$ & $4(8)$ & N/A & 0.085 \\
\hline LCX & $13(25)^{\#}$ & $4(8)$ & N/A & 0.017 \\
\hline RCA & $8(15)$ & $7(14)$ & N/A & 0.780
\end{tabular}

HSL, high-grade stenotic lesions(grade 1,2 or 3); LMCA, left main coronary artery; RCA, right coronary artery; LAD, left anterior descending artery; LCX, left circumflex artery. High grade stenotic lesions

(HSL) were defined as total or subtotal obstruction with antegrade flow of TIMI grade 0,1 , or 2 . ${ }^{\#} P<$ 0.05 compared with the 3VD-non-DM group.

\subsection{Echocardiography characteristics of the study population}

The baseline echocardiographic parameters are presented in Table 3. The relative wall thickness IVS and LVPW were significantly larger, and the peak velocities of late $(A)$ diastolic flow and E/e' ratio were higher in the 3VD-DM and 3VD-non-DM groups, compared with the control patient. The E/A ratio and peak 
velocities of early (E) of patients with 3VD-non-DM was significantly lower than control patients. However, there was no significant difference of these parameters between the 3VD-DM and the 3VD-non-DM groups.

Table 3

Echocardiographic parameters of the study population

\begin{tabular}{lllll}
\hline Parameters & $\begin{array}{l}\text { 3VD-DM } \\
(\mathrm{n}=53)\end{array}$ & $\begin{array}{l}\text { 3VD-non-DM } \\
(\mathrm{n}=50)\end{array}$ & $\begin{array}{l}\text { Control } \\
(\mathrm{n}=30)\end{array}$ & $P$-value \\
\hline IVS $(\mathrm{mm})$ & $0.96 \pm 0.10 *$ & $0.91 \pm 0.15 *$ & $0.86 \pm 0.11$ & 0.004 \\
\hline LVPW $(\mathrm{mm})$ & $0.95 \pm 0.10 *$ & $0.90 \pm 0.13$ & $0.87 \pm 0.13$ & 0.027 \\
\hline $\begin{array}{l}\text { LV end-diastolic } \\
\text { dimension }(\mathrm{mm})\end{array}$ & $4.73 \pm 0.36$ & $4.69 \pm 0.46$ & $4.74 \pm 0.33$ & 0.847 \\
\hline LV DEV $(\mathrm{mL})$ & $102 \pm 26$ & $108 \pm 29$ & $105 \pm 25$ & 0.654 \\
\hline LV ESV $(\mathrm{mL})$ & $42 \pm 16$ & $45 \pm 15$ & $45 \pm 13$ & 0.226 \\
\hline LV ejection fraction(\%) & $66 \pm 9$ & $64 \pm 8$ & $68 \pm 7$ & 0.103 \\
\hline E (cm/sec) & $63.09 \pm 14.04$ & $60.80 \pm 17.27 *$ & $72.21 \pm 25.84$ & 0.039 \\
\hline A (cm/sec) & $83.91 \pm 18.91 *$ & $83.78 \pm 17.26 *$ & $70.42 \pm 23.61$ & 0.009 \\
\hline E/A ratio & $0.80 \pm 0.29 *$ & $0.76 \pm 0.32 *$ & $1.07 \pm 0.41$ & 0.001 \\
\hline E/e' ratio & $12.22 \pm 2.72 *$ & $12.54 \pm 3.48 *$ & $9.85 \pm 3.17$ & 0.002 \\
\hline LA & $3.85 \pm 0.49 *$ & $3.73 \pm 0.50 *$ & $3.50 \pm 0.39$ & 0.019 \\
\hline$* P<0.05$ compared with the control group. & & &
\end{tabular}

\subsection{Comparison of global and segmental peak systolic longitudinal strains of the study population}

Global and segmental PSLSs of all subjects are shown in Table 4. Both the 3VD-DM and 3VD-non-DM patients demonstrated significantly lower longitudinal strain values (GLS and segmental PSLSs), compared with control group. But the longitudinal strain of the 3VD-DM was significantly lower than of those without DM, especially in GLS $(15.87 \pm 2.51$ vs. $17.56 \pm 2.72 ; P<0.05)$ and apical PSLSs $(17.05 \pm$ 4.64 vs. $20.62 \pm 4.78 ; P<0.05)$. Furthermore, no difference of basal and middle PSLSs was observed between the 3 VD groups with DM or without DM. 
Table 4

Echocardiographic parameters of the study population

\begin{tabular}{lcccc}
\hline Parameters & 3VD-DM $(\mathrm{n}=53)$ & 3VD-non-DM $(\mathrm{n}=50)$ & Control $(\mathrm{n}=30)$ & $P$-value \\
\hline Global PSLS (\%) & $15.87 \pm 2.51^{*} \#$ & $17.56 \pm 2.72^{*}$ & $20.48 \pm 2.06$ & $<0.001$ \\
\hline Basal PSLS (\%) & $14.43 \pm 2.83^{*}$ & $14.96 \pm 3.13^{*}$ & $18.32 \pm 2.43$ & $<0.001$ \\
\hline Middle PSLS (\%) & $15.74 \pm 2.92^{*}$ & $16.90 \pm 2.88^{*}$ & $20.61 \pm 2.05$ & $<0.001$ \\
\hline Apical PSLS (\%) & $17.05 \pm 4.64^{*} \#$ & $20.62 \pm 4.78^{*}$ & $23.62 \pm 2.98$ & $<0.001$ \\
\hline Mid- and basal PSLS (\%) & $15.08 \pm 2.75^{*}$ & $15.89 \pm 2.84^{*}$ & $19.36 \pm 2.07$ & $<0.001$ \\
\hline
\end{tabular}

PSLS, peak systolic longitudinal strains; ${ }^{*} P<0.05$ compared with the control group; ${ }^{\#} P<0.05$ compared with the 3VD-non-DM group.

In figure 1, representative bull's-eye displays shows the difference images about the 3VD-DM patient and the normal subject. The images of the 3VD-DM patient showed decreased segmental PSLSs and three epicardial vessels stenosis in the coronary angiography (figure $1 \mathrm{~B}$ ).

\subsection{The effect of the duration of DM on the GLS in the 3VD patients}

The effect of the duration of DM on the 3VD patients was evaluated by strain analysis. According to the duration years of DM, 3VD-DM patients were divided into two subgroups: $D M<5$ years and $D M \geq 5$ years. In figure 2, GLS was significantly lower in the diabetic group with longer disease duration (DM $\geq 5$ years), than the short diabetic duration group (DM $<5$ years) $(14.25 \pm 2.31 \%$ vs. $16.65 \pm 1.96 \%, P=0.007)$ and the 3 VD-non-DM $(14.25 \pm 2.31 \%$ vs. $17.56 \pm 2.72 \%, P<0.001)$. In the two subgroups, the global, mid and apical PSLSs of those with $D M \geq 5$ years was significantly lower than of those with $D M<5$ years. These findings indicate that more damaged GLS and segmental PSLSs were observed in the 3VD patients with longer DM duration.

\subsection{The effect of the level of glucose on the GLS in the 3VD patients}

The concentration of Hemoglobin A1c ( $\mathrm{HbA} 1 \mathrm{c})$ is widely used for the routine monitoring of long-term

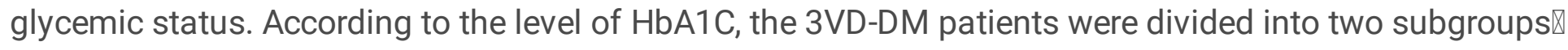
$\mathrm{HbA} 1 \mathrm{C}<7$ group and $\mathrm{HbA} 1 \mathrm{C} \geq 7$ group. The comparison of longitudinal strain values were illustrated in Figure 3. It showed that only the GLS and apical PSLS in the 3VD-DM patients with $\mathrm{HbA} 1 \mathrm{C} \geq 7$ was lower than patients without $\mathrm{DM}(15.34 \pm 1.97$ vs. $17.56 \pm 2.72, P=0.008 ; 16.12 \pm 4.59$ vs. $20.62 \pm 4.78, P=0.001)$. However, in the two subgroups, there was no significant difference of GLS and segmental PSLSs between 
the 3VD-DM patients with $\mathrm{HbA} 1 \mathrm{C}<7$ and with $\mathrm{HbA} 1 \mathrm{C} \geq 7$. These findings indicate that no significant differences of GLS and segmental PSLSs were observed in the 3VD-DM patients with different HbA1c levels.

\subsection{Reproducibility}

There were good intra-observer and inter-observer correlation for strain measurement. The intraclass correlation coefficients for inter-observer reproducibility of GLS were 0.979 ( $95 \%$ confidential interval: 0.946-0.989), and the corresponding coefficients for intra-observer reproducibility were 0.970 (95\% confidential interval: 0.922-0.986).

\section{Discussion}

The present study represents an assessment of LV myocardial deformation changes by traditional standard echocardiography and speckle tracking echocardiography of the 3VD patients with and without DM. The standard echocardiography demonstrated no significant difference of parameters between the 3VD-DM and the 3VD-non-DM groups. By the 2D STE, it indicates that the GLS and segmental PSLSs of 3VD patients are significantly lower than the normal subjects, and much lower longitudinal strain values are found in the 3VD-DM patients than the 3VD-non-DM patients. As to evaluate the effect of the duration of DM on the 3VD patients, it is observed that the significantly worse GLS is found in the 3VD patients with the duration of $D M \geq 5$ years than with the duration of $D M<5$ year. However, as to the effect of the glucose control level on the 3VD patients, it is found that there is no significant difference of GLS and segmental PSLSs are observed between the patients with $\mathrm{HbA} 1 \mathrm{C} \geq 7$ or $\mathrm{HbA} 1 \mathrm{C}<7$.

\subsection{LV longitudinal function in T2DM}

In the past three decades, a number of experimental, pathological, epidemiological and clinical data confirmed the association of DM with myocardial dysfunction. According to the standard echocardiography in our study, it demonstrated the diastolic dysfunction of the 3VD-DM and the 3VDnon-DM patients, compared with the control group. However, these differences weren't been found between the 3VD-DM and the 3VD-non-DM patients.

Echocardiography-based speckle-tracking strain imaging is an emerging modality to assess LV function. The use of noninvasive strain imaging may provide added information to aid in perioperative risk stratify caption and management for these high-risk patients $\llbracket$ such as DM [16] [17]. LV longitudinal myocardial systolic dysfunction, as assessed in terms of lower GLS, has been identified decreased in DM patients [18]. It has been reported that DM patients have lower longitudinal myocardial mechanics, circumferential and rotational mechanics [19]. And diabetic patients might have dysfunction apparent in the longitudinal direction [20]. Several studies have confirmed that the LV function in diabetic patients gradually develop to dysfunction, and eventually develop symptoms of heart failure [2]. Nakai et al. 
reported that GLS in T2DM patients was significantly lower than that in age-matched normal subjects in spite of similar LVEF [20]. While, Zoroufian et al. also found that segmental and global systolic longitudinal strains were decreased in diabetic patients with normal coronary artery and EF value [21]. Therefore, the speckle tracking echocardiography could be more sensitive to detect the changes of DM for impaired LV function.

\subsection{LV longitudinal function in 3VD patients with T2DM}

The diffuse multi-vessel atherosclerosis is frequently present in the T2DM patients $邓$ before symptoms of ischemia occur [22]. The frequency of 3VD in patients with DM comorbidity was much higher. Sometimes, the CAD in diabetic patients is missed or delayed since the typical symptoms of myocardial ischemia are often masked. The speckle-tracking strain was further used to evaluate the features of these patients.

Previously studies reported that the patients with both CAD and DM had more impaired PSLSs than patients with either condition alone[23]. Limited data was collected to focus on the 3VD patients and to differentiate between the 3VD-DM patients and the 3VD-non-DM patients. Interesting, the findings of our present study extend the available knowledge, in which the global and apical PSLSs of the 3VDDM patients was significantly lower than the 3VD-non-DM patients. Our study showed that the patients with 3VD-DM had significantly lower longitudinal strain values (global and segmental PSLSs) compared with the normal subjects.

The reasons of the worse GLS in 3VD-DM patients were prone to impaired cardiac systolic and diastolic function. A number of mechanisms have been reported to play an important role in DM patients' LV longitudinal dysfunction [24]. These changes are observed as changes in free acid metabolism, increased apoptosis, activation of the renin angiotensin system, autonomic neuropathy and increased oxidative stress among others [7] [25]. All these underlying pathogenetic conditions change the cardiac structure and lead to myocardial ischemia [26]. Since the 3VD lead to the more seriously myocardial ischemia, the damaged longitudinal strain could be observed more obviously in both 3VD and DM patients.

\subsection{The effect of the duration and the glucose control level of DM on the GLS of 3VD patients}

Several other studies found that the impairment of the GLS in asymptomatic DM patients was progressed with time[27]. The effect of the DM duration on the 3VD patients is unknown. Our study investigated the GLS changes in 3VD patients with different DM duration. It showed the 3VD patients with $\mathrm{DM} \geq 5$ years had significantly lower longitudinal strain values compared with the duration of $D M<5$ years, especially in global, mid and apical PSLSs. Other researches demonstrated the duration of diabetic disease was the only independent predictor for the decrease in GLS [20], similar with our results. It seems that the longer DM duration cause worse GLS, even in the 3VD patients. It is postulated that prolonged 
exposure to hyperglycemia can epigenetically modify gene expression profiles in human cells and that hyperglycemic memory is sustained even after hyperglycemic control is therapeutically achieved [27]. That is why the longer DM duration cause worse GLS in the 3VD patients.

Then, the effect of the glucose control level on the 3VD patients with DM was evaluated. A study showed that diabetes with poor blood glucose control, as defined by $\mathrm{HbA} 1 \mathrm{c} \geq 7 \%$, leads to reductions of $\mathrm{LV}$ systolic strain [28]. Other clinical trials have shown that normalization of blood glucose failed to reduce cardiovascular outcomes in the diabetic population [29]. In our study, we found that there was no significant difference between the $3 \mathrm{VD}$ patients with $\mathrm{HbA} 1 \mathrm{C} \geq 7$ or $\mathrm{HbA} 1 \mathrm{C}<7$. This result demonstrates the glucose control has limited effect on the GLS in the 3VD patients. It may come from that myocardial ischemia was severe because of 3VD, in which it can cause the decreased GLS. Relatively, the damage of uncontrolled glucose level on the LV strain in the 3VD-DM patients maybe limited.

\subsection{Limitations}

There are several limitations to our study. First, the LV strain in the radial and circumferential directions was not evaluated. The automated algorithm used in the present study only permits the assessment of longitudinal LV strain. Then, patients with and without DM differed with respect to some clinical characteristics, including age, con-founding comorbid conditions such as hypertension and some medications treatment as out lined inTable1. Although these differences were due mostly to DM, it is also possible that the differences observed in longitudinal strain might be due to the aforementioned differences in clinical characteristics. In our study, patients in the DM group had a higher incidence of hypertension than those in the non-DM group, which may influence the strain difference between groups with and without DM [30]. However, exclusion of hypertensive patients from the study is unlikely because the incidence of hypertension is very high in patients with CAD. Therefore, the impairment of strains may not be specific to CAD or DM, and further investigations are needed to validate our findings.

\section{Conclusions}

The present study found that longitudinal strain is impaired mostly in the patients with both 3VD and DM compared with patients with either condition alone, indicating the synergistic effect of 3VD and DM on the impairment of strain. The duration of DM is a significantly factor in GLS damage; on the contrary, the glucose level of diabetics has limited effect on the 3VD patients. GLS at rest might be a useful parameter in the detection of three-vessel CAD in patients with DM.

\section{Abbreviations}

3VD: three-vessel disease; CAD: coronary artery disease; T2DM: type 2 diabetes mellitus; LV: left ventricular; 2-D STE: two-dimensional speckle tracking echocardiography; GLS: global longitudinal strain; PSLSs: peak systolic longitudinal strains; CAG: coronary angiography; LVEF: left ventricular ejection 
fraction; 3VD-DM:3VD with type 2 DM; 3VD-non-DM: 3VD without type 2 DM; HSL: high-grade stenotic lesions; HbA1c: Hemoglobin A1c.

\section{Declarations}

\section{Acknowledgements}

The authors are grateful for the support of the entire staff of the Division of Cardiovascular Medicine, Department of Internal Medicine, Tongji Hospital, Huazhong University of Science and Technology.

\section{Authors' contributions:}

Luying Jiang: Writing - review \& editing. Jingbo Liu: Data curation, Project administration, Resources. ZhenJia Yang: Data curation, Investigation. Li Wang: Data curation, Investigation, Supervision. Houjuan Zuo: Conceptualization, Methodology, Formal analysis, Writing - original draft.

\section{Funding}

The project was supported by a grant from the National Natural Science Foundation of China (No 81873535).

\section{Availability of data and materials}

Data sharing not applicable to this article as no datasets were generated or analyzed during the current study.

\section{Ethics approval and consent to participate}

This study was approved by the Research Ethics Committee of Tongji Hospital.

\section{Consent for publication}

The consent to publish was obtained from all participants in this study.

\section{Competing interests}

The authors declare that they have no competing interests. 


\section{References}

1. Danaei G, Finucane MM, Lu Y, Singh GM, Cowan MJ, Paciorek CJ, Lin JK, Farzadfar F, Khang YH, Stevens GA, et al. National, regional, and global trends in fasting plasma glucose and diabetes prevalence since 1980: systematic analysis of health examination surveys and epidemiological studies with 370 country-years and 2.7 million participants. Lancet. 2011;378(9785):31-40.

2. Chareonthaitawee P, Sorajja P, Rajagopalan N, Miller TD, Hodge DO, Frye RL, Gibbons RJ. Prevalence and prognosis of left ventricular systolic dysfunction in asymptomatic diabetic patients without known coronary artery disease referred for stress single-photon emission computed tomography and assessment of left ventricular function. Am Heart J. 2007;154(3):567-74.

3. Aksakal E, Akaras N, Kurt M, Tanboga IH, Halici Z, Odabasoglu F, Bakirci EM, Unal B. The role of oxidative stress in diabetic cardiomyopathy: an experimental study. Eur Rev Med Pharmacol Sci. 2011;15(11):1241-6.

4. Yoon YS, Uchida S, Masuo O, Cejna M, Park JS, Gwon HC, Kirchmair R, Bahlman F, Walter D, Curry C, et al. Progressive attenuation of myocardial vascular endothelial growth factor expression is a seminal event in diabetic cardiomyopathy: restoration of microvascular homeostasis and recovery of cardiac function in diabetic cardiomyopathy after replenishment of local vascular endothelial growth factor. Circulation. 2005;111(16):2073-85.

5. Miki T, Yuda S, Kouzu H, Miura T. Diabetic cardiomyopathy: pathophysiology and clinical features. Heart Fail Rev. 2013;18(2):149-66.

6. Consensus development conference on the diagnosis of coronary heart disease in people with diabetes: 10-11 February 1998, Miami, Florida. American Diabetes Association. Diabetes Care 1998, 21(9):1551-1559.

7. Authors/Task Force M, Ryden L, Grant PJ, Anker SD, Berne C, Cosentino F, Danchin N, Deaton C, Escaned J, Hammes HP, et al. ESC Guidelines on diabetes, pre-diabetes, and cardiovascular diseases developed in collaboration with the EASD: the Task Force on diabetes, pre-diabetes, and cardiovascular diseases of the European Society of Cardiology (ESC) and developed in collaboration with the European Association for the Study of Diabetes (EASD). Eur Heart J. 2013;34(39):3035-87.

8. Escaned J, Collet C, Ryan N, De Maria GL, Walsh S, Sabate M, Davies J, Lesiak M, Moreno R, CruzGonzalez I, et al. Clinical outcomes of state-of-the-art percutaneous coronary revascularization in patients with de novo three vessel disease: 1-year results of the SYNTAX II study. Eur Heart J. 2017;38(42):3124-34.

9. Ahmed F, Khan MS, Ali Shah SD, Jalbani J, Ali Shah A, Shaikh GA. Frequency of Three-Vessel Disease Among Patients With Non-ST Segment Elevation Myocardial Infarction. Cureus. 2020;12(11):e11634.

10. Longobardo L, Suma V, Jain R, Carerj S, Zito C, Zwicke DL, Khandheria BK. Role of Two-Dimensional Speckle-Tracking Echocardiography Strain in the Assessment of Right Ventricular Systolic Function and Comparison with Conventional Parameters. J Am Soc Echocardiogr. 2017;30(10):937-46 e936. 
11. Smiseth OA, Torp H, Opdahl A, Haugaa KH, Urheim S. Myocardial strain imaging: how useful is it in clinical decision making? Eur Heart J. 2016;37(15):1196-207.

12. 36th International Symposium on Intensive Care and Emergency Medicine: Brussels, Belgium. 15-18 March 2016. Crit Care 2016, 20(Suppl 2):94.

13. Zuo HJ, Yang XT, Liu QG, Zhang Y, Zeng HS, Yan JT, Wang DW, Wang H. Global Longitudinal Strain at Rest for Detection of Coronary Artery Disease in Patients without Diabetes Mellitus. Curr Med Sci. 2018;38(3):413-21.

14. Austen WG, Edwards JE, Frye RL, Gensini GG, Gott VL, Griffith LS, McGoon DC, Murphy ML, Roe BB. A reporting system on patients evaluated for coronary artery disease. Report of the Ad Hoc Committee for Grading of Coronary Artery Disease, Council on Cardiovascular Surgery, American Heart Association. Circulation. 1975;51(4 Suppl):5-40.

15. Lang RM, Badano LP, Mor-Avi V, Afilalo J, Armstrong A, Ernande L, Flachskampf FA, Foster E, Goldstein SA, Kuznetsova T, et al. Recommendations for cardiac chamber quantification by echocardiography in adults: an update from the American Society of Echocardiography and the European Association of Cardiovascular Imaging. J Am Soc Echocardiogr. 2015;28(1):1-39 e14.

16. Howard-Quijano K, Salem A, Barkulis C, Mazor E, Scovotti JC, Ho JK, Shemin RJ, Grogan T, Elashoff D, Mahajan A. Preoperative Three-Dimensional Strain Imaging Identifies Reduction in Left Ventricular Function and Predicts Outcomes After Cardiac Surgery. Anesth Analg. 2017;124(2):419-28.

17. Gozdzik A, Letachowicz K, Grajek BB, Plonek T, Obremska M, Jasinski M, Gozdzik W. Application of strain and other echocardiographic parameters in the evaluation of early and long-term clinical outcomes after cardiac surgery revascularization. BMC Cardiovasc Disord. 2019;19(1):189.

18. Capotosto L, D'Ettorre G, Ajassa C, Cavallari N, Ciardi MR, Placanica G, Ricci S, Lucchetti P, Tanzilli G, Mangieri E, et al. Assessment of Biventricular Function by Three-Dimensional Speckle Tracking Echocardiography in Adolescents and Young Adults with Human Immunodeficiency Virus Infection: A Pilot Study. Cardiology. 2019;144(3-4):101-11.

19. Karagoz A, Bezgin T, Kutluturk I, Kulahcioglu S, Tanboga IH, Guler A, Karabay CY, Oduncu V, Aksoy H, Kirma C. Subclinical left ventricular systolic dysfunction in diabetic patients and its association with retinopathy: A 2D speckle tracking echocardiography study. Herz. 2015;40(Suppl 3):240-6.

20. Nakai H, Takeuchi M, Nishikage T, Lang RM, Otsuji Y. Subclinical left ventricular dysfunction in asymptomatic diabetic patients assessed by two-dimensional speckle tracking echocardiography: correlation with diabetic duration. Eur J Echocardiogr. 2009;10(8):926-32.

21. Zoroufian A, Razmi T, Taghavi-Shavazi M, Lotfi-Tokaldany M, Jalali A. Evaluation of subclinical left ventricular dysfunction in diabetic patients: longitudinal strain velocities and left ventricular dyssynchrony by two-dimensional speckle tracking echocardiography study. Echocardiography. 2014;31(4):456-63.

22. Mochizuki Y, Tanaka H, Matsumoto K, Sano H, Toki H, Shimoura H, Ooka J, Sawa T, Motoji Y, Ryo K, et al. Clinical features of subclinical left ventricular systolic dysfunction in patients with diabetes mellitus. Cardiovasc Diabetol. 2015;14:37. 
23. Zuo H, Yan J, Zeng H, Li W, Li P, Liu Z, Cui G, Lv J, Wang D, Wang H. Diagnostic power of longitudinal strain at rest for the detection of obstructive coronary artery disease in patients with type 2 diabetes mellitus. Ultrasound Med Biol. 2015;41(1):89-98.

24. Bando YK, Murohara T. Diabetes-related heart failure. Circ J. 2014;78(3):576-83.

25. Yancy CW, Jessup M, Bozkurt B, Butler J, Casey DE Jr, Drazner MH, Fonarow GC, Geraci SA, Horwich T, Januzzi JL, et al. 2013 ACCF/AHA guideline for the management of heart failure: a report of the American College of Cardiology Foundation/American Heart Association Task Force on Practice Guidelines. J Am Coll Cardiol. 2013;62(16):e147-239.

26. Sacre JW, Franjic B, Jellis CL, Jenkins C, Coombes JS, Marwick TH. Association of cardiac autonomic neuropathy with subclinical myocardial dysfunction in type 2 diabetes. JACC Cardiovasc Imaging. 2010;3(12):1207-15.

27. Wang Y, Tar MT, Davies KP. Hyperglycemic memory in the rat bladder detrusor is associated with a persistent hypomethylated state. Physiol Rep. 2020;8(22):e14614.

28. Zhang X, Wei X, Liang Y, Liu M, Li C, Tang H. Differential changes of left ventricular myocardial deformation in diabetic patients with controlled and uncontrolled blood glucose: a three-dimensional speckle-tracking echocardiography-based study. J Am Soc Echocardiogr. 2013;26(5):499-506.

29. Roos CJ, Scholte AJ, Kharagjitsingh AV, Bax JJ, Delgado V. Changes in multidirectional LV strain in asymptomatic patients with type 2 diabetes mellitus: a 2-year follow-up study. Eur Heart $\mathrm{J}$ Cardiovasc Imaging. 2014;15(1):41-7.

30. Fung MJ, Thomas L, Leung DY. Left ventricular function and contractile reserve in patients with hypertension. Eur Heart J Cardiovasc Imaging. 2018;19(11):1253-9.

\section{Figures}


A
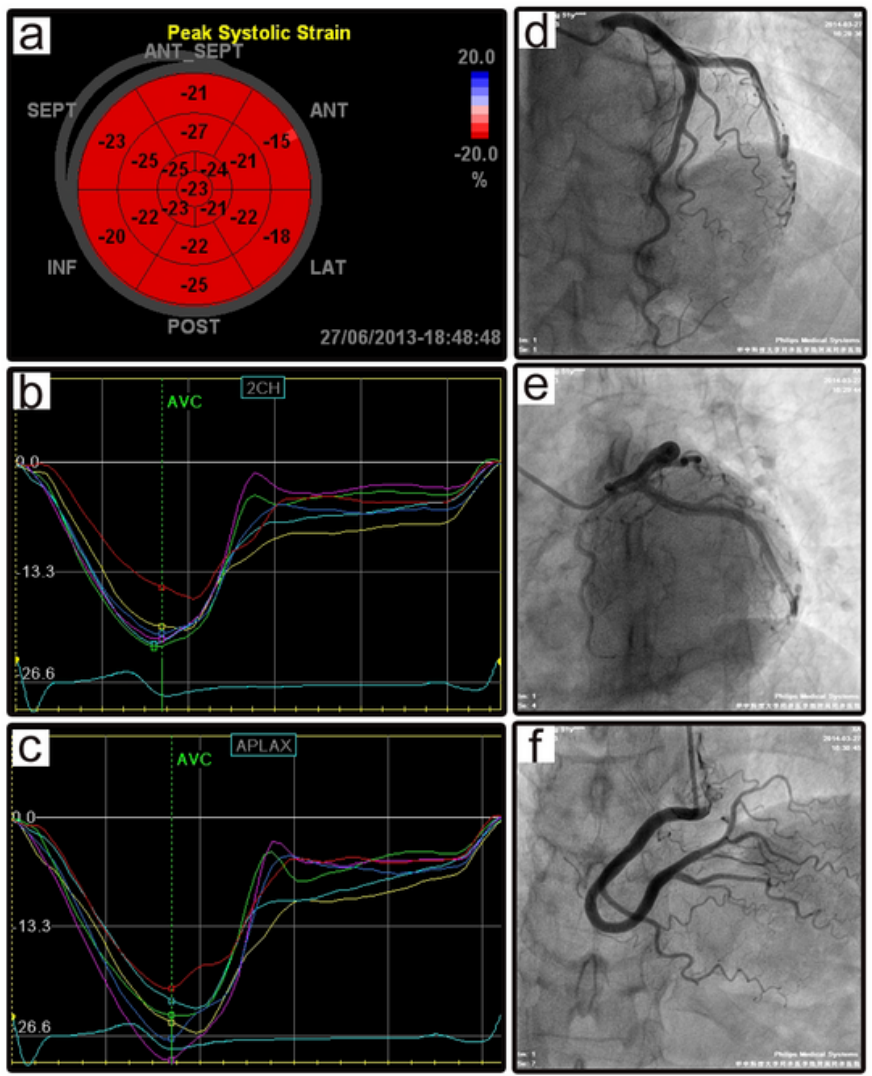

B
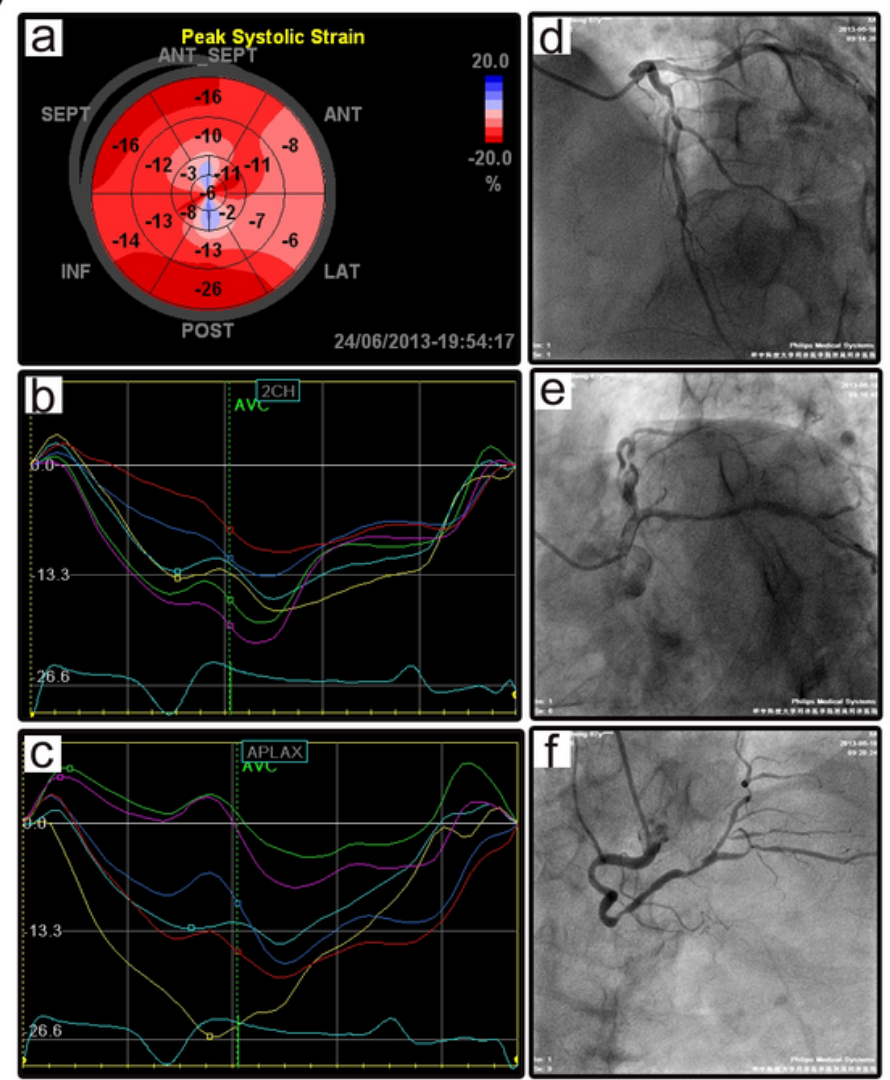

\section{Figure 1}

Representative longitudinal strains by 2D-STE presented as 'bull's eye' displays. The representative bull'seye displays with segmental PSLSs from selected patients along with coronary angiogram and speckle tracking in color-coded two-dimensional display of the LV and corresponding time-strain curves derived from the apical two-chamber view. (A) Images obtained from a normal patient who had no significant coronary stenosis. The polar map reveals no significant reduction in longitudinal strain. (B) Images obtained from a patient with 3VD. The polar map reveals a significant reduction in longitudinal strain. (a) The 17-segment polar map is presented as a "bull's-eye" display with the segmental and global values of PSLS; (b) Left ventricular speckle tracking imaging from the apical two-chamber view by automated function imaging, longitudinal strain curves of each segment; (c) Left ventricular speckle tracking imaging from the aplax view by automated function imaging, longitudinal strain curves of each segment; (d-f) Coronary angiogram of the patient. 
A Global longitudinal strain
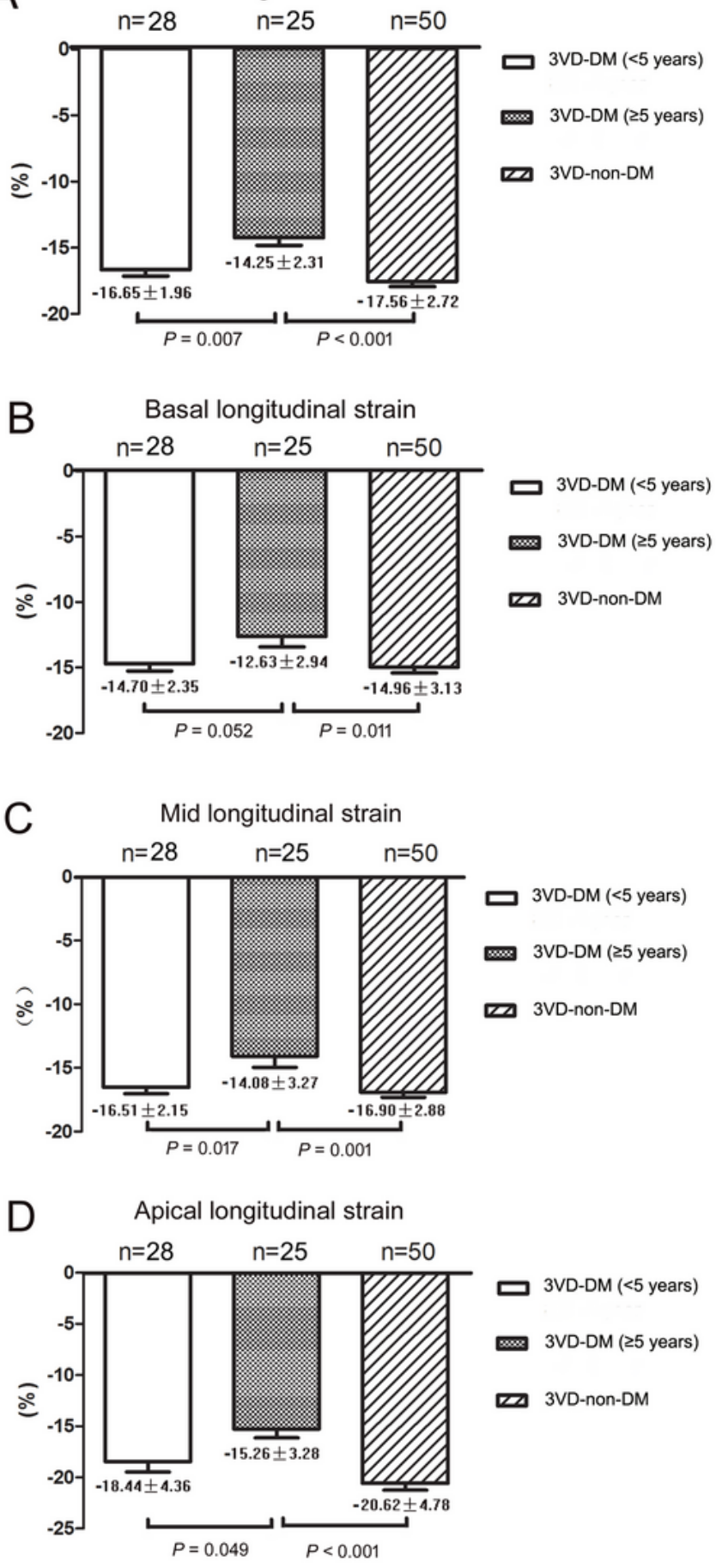

Figure 2

The effect of the duration of DM on the GLS of 3VD patients. Bar Bar graph illustrates the comparison in longitudinal strain values among the 3VD-DM patients with duration of DM<5, the 3VD-DM patients with duration of $\mathrm{DM} \geq 5$ years, and the 3VD-non-DM group. 
A Global longitudinal strain

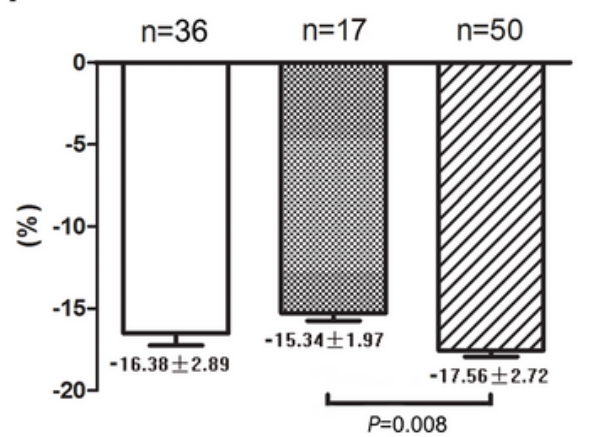

B

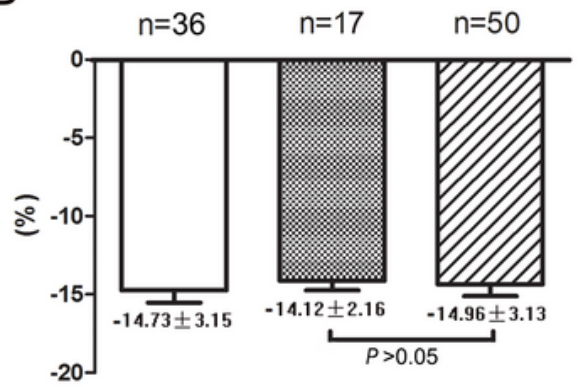

$$
\begin{aligned}
& \text { 3VD-DM (HbA1C } 27) \\
& \text { 3VD-non-DM }
\end{aligned}
$$
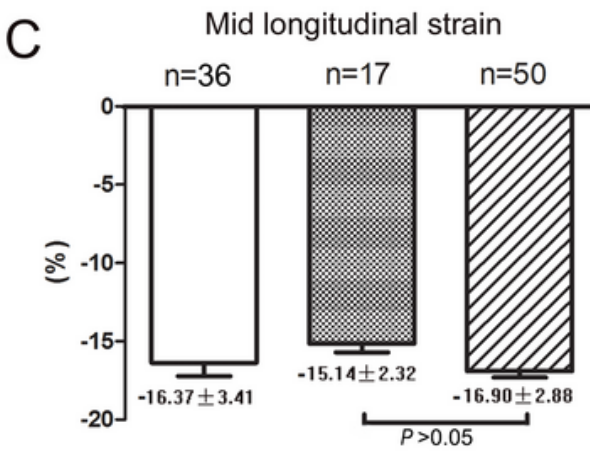

$\square$ 3VD-DM (HbA1C<7)

3VD-DM (HbA1C 27$)$

Z 3VD-non-DM

D

Apical longitudinal strain

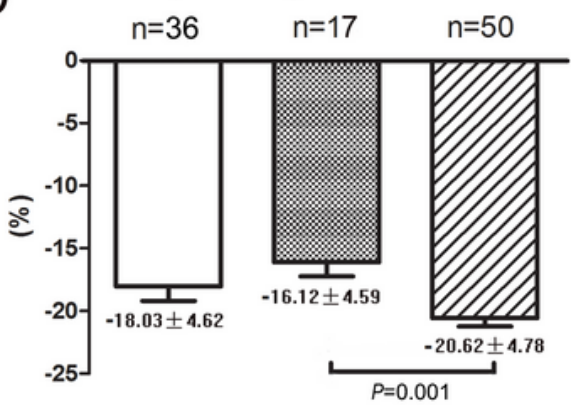

$\square$ 3VD-DM (HbA1C<7)
3VD-DM (HbA1C 27$)$
3VD-non-DM

$\square$ 3VD-DM (HbA1C<7)

3VD-DM (HbA1C 27$)$

שV 3VD-non-DM

\section{Figure 3}

The effect of the glucose control level of DM on the GLS of 3VD patients. Bar graph illustrates the comparison in longitudinal strain values among the among the 3VD-DM patients with $\mathrm{HbA} 1 \mathrm{C}<7$, the 3VDDM patients with $\mathrm{HbA} 1 \mathrm{C} \geq 7$, and the $3 \mathrm{VD}$-non-DM group. 